\title{
A PRELIMINARY REPORT ON THE LACK OF TOXICITY OF A PREPARATION OF TOTAL RAUWOLFIA ALKALOIDS
}

\author{
BY
}

\author{
HOMAI M. COLABAWALLA \\ From Mapperley Hospital, Nottingham
}

In disturbed patients with mental illness of many kinds, the benefits of reserpine are well recognized, though in many cases the side-effects are so unpleasant as to outweigh the advantages (Hambling, 1957). Besides reserpine, other Rauwolfia alkaloids are active (Schneider, Plummer, Earl, and Gaunt, 1955); indeed the whole root has been used in India for centuries by Ayurvedic physicians under the popular name of Pagal-ka-deva, or insanity herbs.

It was thought that a preparation containing all these alkaloids might be free from some of the sideeffects of reserpine alone, as papaveretum tends to cause fewer side-effects than morphine (Douthwaite, 1957). Such preparations include " raudixin " supplied in tablets containing $50 \mathrm{mg}$. of the crude root, i.e., about $0.4 \mathrm{mg}$. of the total alkaloids, and " serpina ", supplied in tablets containing $4 \mathrm{mg}$. of the total alkaloids.* Kline (1954) used small doses of raudixin and reserpine; apparently he found little difference. Serpina has been investigated in the treatment of hypertension and mental illness, and is said to be relatively free from toxic effect (Vakil, 1949; Klausgraber, 1953; Wilkins, 1953; Wilkins and Judson, 1953). I report here a preliminary clinical investigation in mental patients.

In the first experiment " serpina ", reserpine, and a placebo were given to psychotic patients and the response and side-effects compared.

*These include reserpine, reserpinine, ajmaline, ajmalinine, ajmalicine, isoajmaline, neoajmaline, serpentine, serpentinine, sarpagine, rauwolfinine, raupine, corynanthine, isorauhimbine, yohimbine, thebaine, papaverine, and reserpic acid methyl ester.
In the second experiment, in a dose found safe and effective in the first experiment, " serpina " was given to a larger number of patients for a longer period.

\section{First Experiment}

Thirty-six chronic psychotic men, all restless and excitable, were divided into three groups $(A, B$, and $C$ ) according to the alphabetical order of surnames, except for some adjustment to ensure that each group contained patients of about the same age. Of the Group $A$ patients, 11 were schizophrenic and one epileptic. Of the schizophrenics, four had had leucotomies; one of these four and one other were taking chlorpromazine. Group $B$ contained 11 schizophrenics and a paraphrenic; four of the schizophrenics had had leucotomies and one was taking chlorpromazine. Group $C$ contained 11 schizophrenics and a manic-depressive; four schizophrenics had had leucotomies; one of these, and one other, were taking chlorpromazine. The chlorpromazine was continued throughout the experiment, in view of the reported adverse effects of sudden withdrawal (Trethowan and Scott, 1955). The groups were well matched (Table I) in age, duration of symptoms, presumed basic intelligence, and behaviour rating on a modified Elgin scale(Wittmann and Russell, 1942). Similar proportions in each group were employed in similar occupations, e.g., kitchen, farm, etc.

The nurses, who did not know which preparation was which, gave drug and placebo according to a

TABLE I

COMPARABILITY OF THE THREE GROUPS IN FIRST EXPERIMENT

\begin{tabular}{|c|c|c|c|c|c|c|}
\hline \multirow{2}{*}{ Group } & \multicolumn{2}{|c|}{$A$} & \multicolumn{2}{|c|}{$B$} & \multicolumn{2}{|c|}{$C$} \\
\hline & Range & Average & Range & Average & Range & Average \\
\hline $\begin{array}{l}\text { Age (yr.) } \\
\text { Duration of symptoms (yr.) } \\
\text { Behaviour rating* } \\
\text { Assumed } † \text { basic intelligence }\end{array}$ & $\begin{array}{c}25-61 \\
4-33 \\
1 \cdot 5-3 \cdot 7 \\
1-4\end{array}$ & $\begin{array}{r}38 \cdot 9 \\
14 \cdot 2 \\
2 \cdot 5 \\
2 \cdot 9\end{array}$ & $\begin{array}{r}22-61 \\
2-32 \\
1 \cdot 8-3 \cdot 3 \\
1-4\end{array}$ & $\begin{array}{r}37 \cdot 4 \\
14 \cdot 9 \\
2 \cdot 3 \\
3 \cdot 0\end{array}$ & $\begin{array}{c}22-58 \\
3-30 \\
1 \cdot 9-4 \cdot 2 \\
1-4\end{array}$ & $\begin{array}{r}37 \cdot 1 \\
14 \cdot 6 \\
2 \cdot 7 \\
2-5\end{array}$ \\
\hline
\end{tabular}

* One deteriorated, five normal.

† One mentally deficient, three average. 
TABLE II

DOSAGE OF DRUGS AND PLACEBO IN FIRST EXPERIMENT

\begin{tabular}{|c|c|c|c|c|}
\hline \multirow{2}{*}{ Day } & \multicolumn{2}{|c|}{ Group $A$} & \multicolumn{2}{|c|}{ Group $B$ and $C$} \\
\hline & Injections & Tablets & Injections & Tablets \\
\hline $1-10$ & 1 ampoule a.m. & 1 noon & $1 \mathrm{ml}$. a.m. & 1 b.i.d. \\
\hline $\begin{array}{l}11-20 \\
21-91\end{array}$ & 1 ampoule a.m. & $\begin{array}{l}1 \text { p.m. } \\
1 \text { a.m. }\end{array}$ & 1 ml. a.m. & $\begin{array}{l}1 \text { t.i.d. } \\
2 \text { t.i.d. }\end{array}$ \\
\hline
\end{tabular}

fixed time table (Table II). Thus each patient had injections and tablets for 20 days, then tablets only. The nurses also recorded the pulse rate and blood pressure of every patient before injection and an hour after, for the first three days, then weekly; the weight and urine test for sugar (weekly); and behaviour and side-effects.

High doses of the drugs were used. Group $A$ patients were given reserpine $(5 \mathrm{mg}$. in each ampoule and $5 \mathrm{mg}$. in each tablet); Group $B$ patients were given injections of sterile water, and "serpina" tablets (4 mg.); and Group $C$ patients were given injections of sterile water and placebo tablets.

\section{Results}

The nurses could soon tell that Group $A$ was receiving an active drug, because of the high incidence of side-effects. Of the 12 patients, pneumonia developed in three, so that treatment had to be interrupted. Ten patients completed the trial; all had side-effects, including drowsiness, shivering, tremors, epileptic fits, increased salivation, and rigidity, stuffiness of the nose and eyes, oedema of the face and feet, sudden falls in blood pressure, dizziness, and fainting, and diarrhoea and vomiting. In some cases these began three hours after the first injection; in others they were delayed for several days.

After about three weeks, improvement in disturbed behaviour began to be obvious in Groups $A$ and $B$ (Table III). During the second 10 days of

TABLE III

NUMBER OF PATIENTS IMPROVED IN EACH GROUP IN FIRST EXPERIMENT

\begin{tabular}{|c|c|c|c|}
\hline \multirow{2}{*}{$\begin{array}{l}\text { Degree of } \\
\text { Improvement }\end{array}$} & \multicolumn{3}{|c|}{ Group } \\
\hline & $A$ & $B$ & C \\
\hline $\begin{array}{c}\text { Much } \\
\text { Moderate } \\
\text { None } \\
\text { Transferred }\end{array}$ & $\begin{array}{l}1 \\
8 \\
1 \\
2\end{array}$ & $\begin{array}{l}0 \\
8 \\
4 \\
0\end{array}$ & $\begin{array}{l}1 \\
8 \\
9 \\
0\end{array}$ \\
\hline Total & 12 & 12 & 12 \\
\hline
\end{tabular}

the experiment, all patients in Group $A$ passed through the usual " turbulent" phase; this was not seen in any patient in Group $B$ at any stage. Two patients in Group $A$ had oedema of the feet while under treatment, but two in Group $B$, who adopted catatonic postures and habitually had oedema of the feet, were relieved of this during treatment.

In Group $C$ little improvement was seen (except in a patient taking chlorpromazine), and there were no side-effects. There was no striking change in weight in any group.

\section{Second Experiment}

In view of the improvement without side-effects in the patients given the total alkaloid preparation, a further 34 chronic psychotic men were treated with it.

Patients were chosen whose condition had become static and in whom improvement was not expected except through some novel treatment. Their average age was 49 (range 30-67), and they had been in hospital on average for 18 years (range two to 35 ). They were more disturbed than the patients in the first experiment; all were unemployed and unoccupied, and uninterested in their personal appearance. Ten were wet and dirty by day, and nine had to be told when to use the toilet. Seven had to be washed and dressed. A number of them needed sedation ato night, and constant supervision of dress and ap- $\Omega$ pearance. One was destructive, tearing up his clothing, and had to eat alone.

Treatment and Response.-Two $4 \mathrm{mg}$. tablets of "serpina" were given thrice daily, and improvement began to be apparent after about three weeks The unmanageable patients became manageable, and all but three were employed-some without supervision. Most could sleep in unsupervised dormitories, which had previously been impossible. Eighteen were able to shave themselves; none were wet and dirty, none had to be washed or dressed, and a minimum of toilet supervision was needed. There were no impulsive outbursts; the destructive patient no longer tore his suits, and his table manners had improved so much that he could eat with the other patients.

No patients could be discharged (often because they had been in-patients for years and had no homes), but a few were well enough to be allowed out at week-ends for the first time.

Side-effects.-After 22 weeks' treatment, the blood pressures were not materially different, except that in four patients with mild hypertension the pressure had become normal $(190 / 110 \mathrm{~mm}$. $\mathrm{Hg}$ to $130 / 80,180 / 100$ to $116 / 60,150 / 100$ to $114 / 78$, and $140 / 100$ to $114 / 68$ ). In three others it fell appreciably $(130 / 80 \mathrm{~mm}$. $\mathrm{Hg}$ to $96 / 70,125 / 80$ to $90 / 60$, and $114 / 68$ to $80 / 50$ ); two of these had one dizzy spell each. There were no other side-effects at all in the whole series. 
When treatment was stopped after 22 weeks, there was some regression, but the patients had become more amenable to habit training, and have not returned completely to their former condition. A few have been given chlorpromazine with some success.

\section{Discussion}

A preparation of total Rauwolfia alkaloids has been found to be as effective as reserpine in a group of disturbed patients, and strikingly free from sideeffects in this and in a larger group treated for a longer period. As Kline and Stanley (1955) write:

" . . . the problem is not solely whether a preparation such as reserpine will cure an individual patient, but whether the over-all therapeutic picture is improved by the addition. Does it act on large numbers of patients more rapidly, more inexpensively, and more permanently than other forms of treatment for specific conditions ? It is necessary to adhere to the dictum of "the greatest good of the greatest number',"

By these criteria, "serpina" seems to merit a place as a useful drug. More information is needed about the constituent alkaloids, but the results reported here indicate that it is worthy of more extensive trial.

\section{Summary}

In a group of disturbed psychiatric patients the effects were compared of reserpine and " serpina ", a preparation of the total alkaloids of Rauwolfia serpentina Benth. The response to each drug was similar, but " serpina" was free from side-effects.

The response to " serpina" and absence of sideeffects were confirmed in a larger group treated for 22 weeks.

Further trial and investigation of this drug are warranted.

I am indebted to Dr. D. Macmillan, the PhysicianSuperintendent, for his interest and help in these trials, to Dr. D. Moynagh for his cooperation, and to Dr. J. Komieniecki for carrying out psychometric tests on some of these patients, I wish to thank the nurses who made many of the observations.

The " serpina " was kindly supplied by Messrs. Hillside Pharmaceuticals, and the "reserpine" and the placebo tablets by Messrs. Riker.

\section{REFERENCES}

Douthwaite, A. H. (1957). Hale-White's Materia Medica, Pharmacology, and Therapeutics, 30th ed., p. 172. Churchill, London.

Hambling, J. (1957). Lancet, 1, 372.

Klausgraber, F. (1953). Wien. med. Wschr., 103, 430.

Kline, N. (1954). Ann N.Y. Acad. Sci., 59, 107.

Kline, and Stanley, A. M. (1955). Ann. N.Y. Acad. Sci., 61. 85

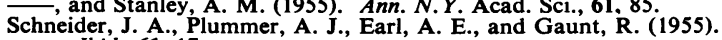
Ibid., 61, 17.

Trethowan, W. H., and Scott, P. A. L. (1955). Lancet, 1, 781.

Vakil, R. J. (1949); Brit. Heart J., 11, 350.

Wilkins, R. W. (1953). Med. Clin. N. Amer., 37, 1303.

W., and Judson, W. E. (1953). New Engl. J. Med., 248, 48

Wittmann, M. P., Russell, J. T. (1942). J. gen. Psychol., 26, 3. 